\title{
Dendritic Spine Abnormalities in Hippocampal CA1 Pyramidal Neurons Underlying Memory Deficits in the SAMP8 Mouse Model of Alzheimer's Disease
}

\author{
Jaume del Valle ${ }^{\mathrm{a}, \mathrm{b}}$, Sergi Bayod ${ }^{\mathrm{a}, \mathrm{b}}$, Antoni Camins $^{\mathrm{a}, \mathrm{b}}$, Carlos Beas-Zárate $^{\mathrm{c}, \mathrm{d}}$, \\ Dulce A. Velázquez-Zamora ${ }^{\mathrm{c}, \mathrm{d}}$, Ignacio González-Burgos ${ }^{\mathrm{c}, \mathrm{d}}$ and Merce Pallàs ${ }^{\mathrm{a}, \mathrm{b}, *}$ \\ ${ }^{a}$ Facultat de Farmàcia, Unitat de Farmacologia i Farmacognòsia, Institut de Biomedicina (IBUB), \\ Universitat de Barcelona, Nucli Universitari de Pedralbes, Barcelona, Spain \\ ${ }^{\mathrm{b}}$ Centros de Investigación Biomédica en Red de Enfermedades Neurodegenerativas (CIBERNED), Barcelona, Spain \\ ${ }^{\mathrm{c} C e n t r o ~ d e ~ I n v e s t i g a c i o ́ n ~ B i o m e ́ d i c a ~ d e ~ O c c i d e n t e, ~ I M S S, ~ D i v i s i o ́ n ~ d e ~ N e u r o c i e n c i a s, ~ G u a d a l a j a r a, ~ J a l ., ~ M e ́ x i c o ~}$ \\ ${ }^{\mathrm{d}}$ Departamento de Biología Celular y Molecular, CUCBA, Universidad de Guadalajara, Guadalajara, Jal., México
}

Accepted 6 June 2012

\begin{abstract}
SAMP8 is a strain of mice with accelerated senescence. These mice have recently been the focus of attention as they show several alterations that have also been described in Alzheimer's disease (AD) patients. The number of dendritic spines, spine plasticity, and morphology are basic to memory formation. In AD, the density of dendritic spines is severely decreased. We studied memory alterations using the object recognition test. We measured levels of synaptophysin as a marker of neurotransmission and used Golgi staining to quantify and characterize the number and morphology of dendritic spines in SAMP8 mice and in SAMR1 as control animals. While there were no memory differences at 3 months of age, the memory of both 6- and 9-month-old SAMP8 mice was impaired in comparison with age-matched SAMR1 mice or young SAMP8 mice. In addition, synaptophysin levels were not altered in young SAMP8 animals, but SAMP8 aged 6 and 9 months had less synaptophysin than SAMR1 controls and also less than 3-month-old SAMP8 mice. Moreover, while spine density remained stable with age in SAMR1 mice, the number of spines started to decrease in SAMP8 animals at 6 months, only to get worse at 9 months. Our results show that from 6 months onwards SAMP8 mice show impaired memory. This age coincides with that at which the levels of synaptophysin and spine density decrease. Thus, we conclude that together with other studies that describe several alterations at similar ages, SAMP8 mice are a very suitable model for studying AD.
\end{abstract}

Keywords: Alzheimer's disease, dendrites, learning, memory, object recognition test, SAMP8, senescence, synaptophysin

\section{INTRODUCTION}

SAMP8 mice are one of the senescence-accelerated strains of mice [1] that have a reduced lifespan and share several characteristics with aged humans such

\footnotetext{
*Correspondence to: Mercè Pallàs, PhD, Facultat de Farmàcia, Unitat de Farmacologia i Farmacognòsia, Universitat de Barcelona, Nucli Universitari de Pedralbes, Barcelona E-08028, Spain. E-mail: pallas@ub.edu.
}

as lordosis, loss of hair, and reduced physical activity $[2,3]$. Studies have also shown that SAMP8 mice present some characteristic neurodegenerative alterations, such as spongy degeneration [4], neuronal cell loss [5], and gliosis [6]. The changes in SAMP8 have been reviewed recently [7], and this strain has been described as a neurodegeneration model.

Furthermore, SAMP8 have been considered to be a sound model for investigating the pathophysiology of the early events in Alzheimer's disease (AD) [8]. 
In fact, these mice have several characteristics that are also seen in AD patients, such as alterations in learning and memory $[9,10]$, amyloid- $\beta$ accumulation [11], an increase in hyperphosphorylated tau [12], cerebral amyloid angiopathy [13], brain blood barrier alterations $[14,15]$, increased oxidative stress in the brain [16], alteration of the cholinergic system [17], a decreased release of neurotransmitters [18, 19], altered emotions and abnormal circadian rhythm [20], and different hippocampal protein aggregates [21]. In fact, due to the early amyloid accumulation in the brain and the spontaneous onset of AD, SAMP8 has also been proposed as an excellent model of late-onset AD [11].

Dendritic spines are tiny protrusions along dendrites that constitute major postsynaptic sites for excitatory synaptic transmission. These spines are highly mobile and can undergo remodeling, even in the adult nervous system. Spine remodeling and the formation of new synapses are activity-dependent processes that provide a basis for memory formation [22, 23]. A loss or alteration of these structures has been described in patients with neurodegenerative disorders such as $\mathrm{AD}$, and in mouse models for these disorders [24]. As synapse loss is strongly correlated with cognitive impairment in $\mathrm{AD}$ [25], synaptic damage and loss are factors that affect the degree of dementia experienced in $\mathrm{AD}$ patients [26].

The aim of this study was to investigate the density and types of dendritic spines in this model of $\mathrm{AD}$ pathology, the types of dendritic spine that is most affected, and its putative influence on memory processes using the object recognition test (ORT) paradigm.

\section{MATERIAL AND METHODS}

\section{Animals}

Twelve to fourteen male 3-, 6-, and 9-month-old SAMR1 and SAMP8 mice were housed in the University of Barcelona facility under controlled temperature and light conditions $\left(21-24^{\circ} \mathrm{C}, 12\right.$-h light/12-h dark cycle). Sentinels from the facility were tested regularly to ensure our facility is virus- and pathogen-free. Six animals from each group were used for Golgi staining and spine studies, and six to eight animals were used in the ORT and the posterior western blots. The care and use of these animals were carried out in accordance with the policy on the use of animals in neuroscience research, published by the Society for Neuroscience. The experimental protocol was approved by the University of Barcelona's Ethics
Committee and complied with the 'Principles of laboratory animal care' and the European Communities Council Directive (86/609/EEC).

\section{Object recognition test}

The test was conducted in a $90^{\circ}$ two arm, $25 \mathrm{~cm}$ long, $20 \mathrm{~cm}$ high maze. The light intensity in the middle of the field was 30 lux. The objects to be discriminated were plastic figures (object A: $5.25 \mathrm{~cm}$ high, object B: $4.75 \mathrm{~cm}$ high). First, mice were individually habituated to the apparatus for $10 \mathrm{~min}$ for three days. $\mathrm{O}$ the fourth day, they were submitted to a $10 \mathrm{~min}$ acquisition trial (first trial) during which they were placed in the maze in the presence of two identical novel objects $(\mathrm{A}+\mathrm{A}$ or $\mathrm{B}+\mathrm{B})$ placed at the end of each arm. A 10 min retention trial (second trial) occurred $2 \mathrm{~h}$ later. During this second trial, the objects $\mathrm{A}$ and $\mathrm{B}$ were placed in the maze and the time that the animal took to explore the new object (tn) and the old object (to) were recorded. A discrimination index (DI) was defined as (tn-to)/(tn + to). In order to avoid object preference biases, objects A and B were counterbalanced so that half of the animals in each experimental group were first exposed to object A and then to object $\mathrm{B}$, whereas the other half saw first object B and then object A. The maze, the surface, and the objects were cleaned with $96^{\circ}$ ethanol between animals, so as to eliminate olfactory cues.

\section{Brain isolation and western blot analysis}

Mice were euthanized one day after the last trial had been conducted, and the brain was quickly removed from the skull. The hippocampus were dissected, frozen in powdered dry ice, and maintained at $-80^{\circ} \mathrm{C}$ until use. When necessary, tissue samples were put into ice-cold conditions and homogenized in lysis buffer containing phosphatase and protease inhibitors (Cocktail II, Sigma). The protein concentration in tissue samples was determined by the Bradford method. A total of $20 \mu \mathrm{g}$ of protein was separated by SDS-PAGE $(5-15 \%)$ and transferred to PVDF membranes (Millipore). The membranes were blocked in 5\% non-fat milk in TBS containing $0.1 \%$ Tween 20 (TBS-T) for $1 \mathrm{~h}$ at room temperature, followed by overnight incubation at $4{ }^{\circ} \mathrm{C}$ with synaptophysin $(1: 500$; Abcam), GADPH ( $1: 2000$; Millipore), and $\beta$-actin $(1: 20000$; Sigma). Membranes were then washed and incubated with secondary antibodies for $1 \mathrm{~h}$ at room temperature. Protein bands were visualized using a chemiluminescence detection kit (Amersham Biosciences). The band 

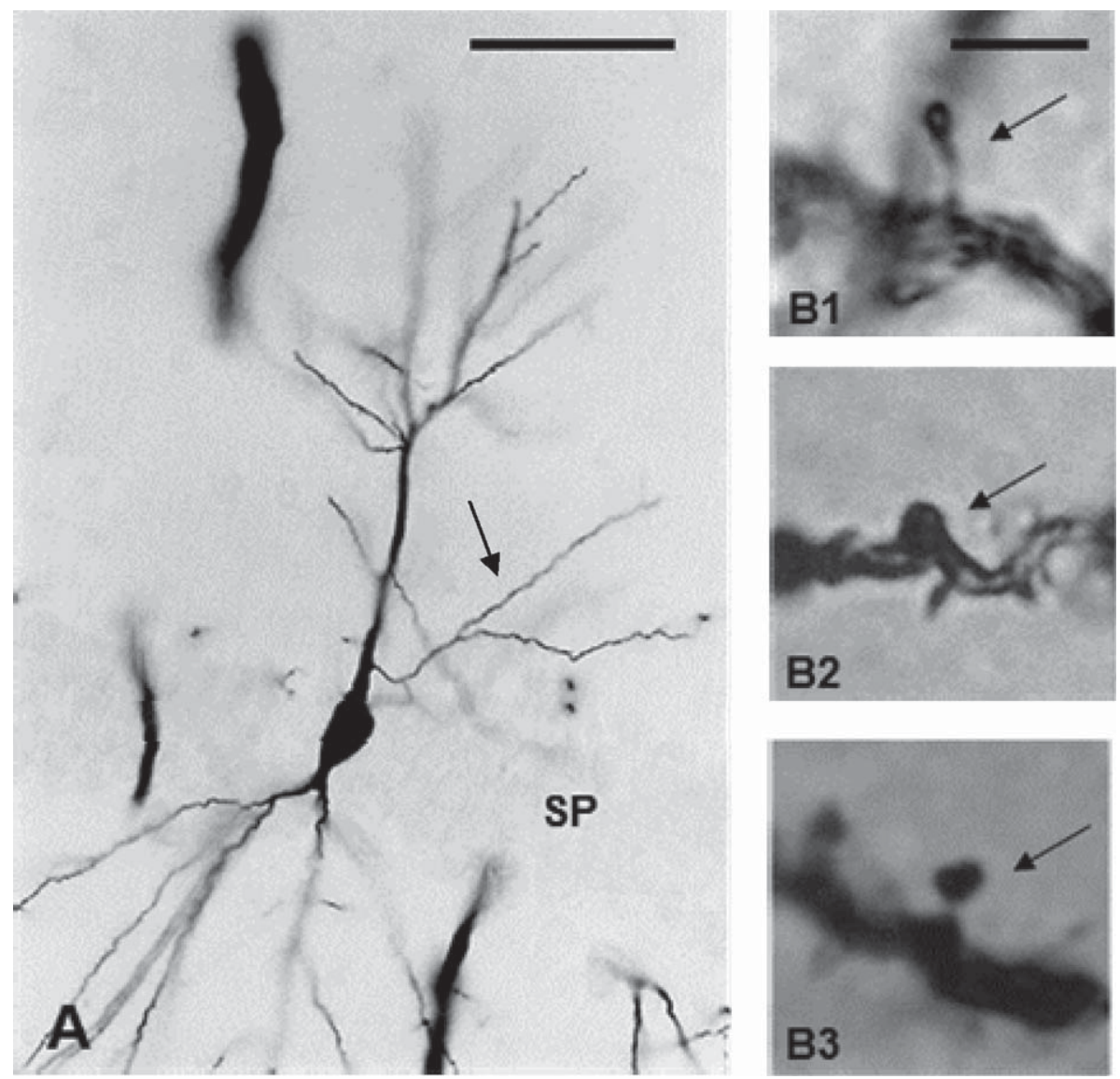

Fig. 1. A) Photomicrograph of a pyramidal neuron from the hippocampal CA1 field of a SAMR1 mouse, similar to those studied in the present work. Dendritic spines were counted in a secondary dendritic segment of $50 \mu \mathrm{m}$ length (arrow). SP: stratum pyramidale. Scale bar: $50 \mu \mathrm{m}$. B) Representative thin (B1), stubby (B2), and mushroom (B3) spines (arrows), like those counted in this study. Scale bar: $2 \mu \mathrm{m}$.

intensities were quantified by densitometric analysis, and values were normalized to $\beta$-actin or GAPDH expression.

\section{Golgi studies}

Animals were anesthetized with $30 \mathrm{mg} / \mathrm{kg}$ intramuscular ketamine and $50 \mathrm{mg} / \mathrm{kg}$ i.p. sodium pentobarbital. Then, they were intracardially perfused with washing phosphate-buffered solution ( $\mathrm{pH} 7.4 ; 0.01 \mathrm{M}$ ), followed by $4 \%$ paraformaldehyde in $0.1 \mathrm{M}$ phosphate buffer $(100 \mathrm{ml} / 100 \mathrm{~g}$ body weight). Both solutions flowed at a rate of $5 \mathrm{~mL} / \mathrm{min}$. Each brain remained for at least $48 \mathrm{~h}$ in $50 \mathrm{~mL}$ of a fresh fixing solution. The bilateral dorsal hippocampi were dissected out and impregnated using a modification of the Golgi method [27]. Several $100 \mu \mathrm{m}$ thick coronal slices were mounted on one slide per animal. The numerical density of spines and the proportion of thin, stubby and mushroom spines (González-Burgos, 2009) were assessed in CA1 pyramidal neurons. Spines were counted in one $50 \mu \mathrm{m}$ segment per cell, located in the middle of one of the secondary dendrites that protrude from the apical dendrite (Fig. 1). Six CA1 pyramidal neurons were studied per animal. Counts were performed by direct observation at $2,000 \times$, using a magnification changer coupled to a light microscope. To ensure the consistency of counting the dendritic spines, an initial "double-blind" study was performed and the reliability index was calculated (number of agreements - number of disagreements/number of agreements). Once a minimum reliability of 0.95 had been reached, the quantification of dendritic spines from the study groups was performed with a "blind" procedure.

\section{Statistical analysis}

The $n$ used for statistical analysis was the number of animals ( $n=6-8$, per experimental group) and the quantitative data are expressed as the mean \pm standard 
error (S.E.M.). The statistical analysis was performed using the one-sample $t$-test, the student's unpaired $t$-test, or analysis of variance (One-way ANOVA), followed by a Bonferroni post hoc test when appropriate. The differences were considered to be statistically significant if $p<0.05$.

\section{RESULTS}

\section{Object recognition test}

During the sample phase of the task, all groups spent the same percentage of time exploring each object, i.e., all animals explored objects similarly both (data not shown). However, while SAMR1 mice showed novel object preference in all age groups during the test phase as their DI was positive and different from zero, 6- and 9-month-old SAMP8 mice showed a DI that was not different from zero, which indicates no preference between the two objects (Fig. 2). A comparison between young 3-month-old SAMP8 mice and 6- and 9-month-old SAMP8 mice show significant differences. In addition, 6- and 9-month-old SAMP8 mice had a significantly lower DI than SAMR1 age-matched mice. This indicates that from 6 months onwards, SAMP8 animals present memory impairment. No differences were found between the 3-month-old mice from either strain, which indicates that no memory differences exist at this point.

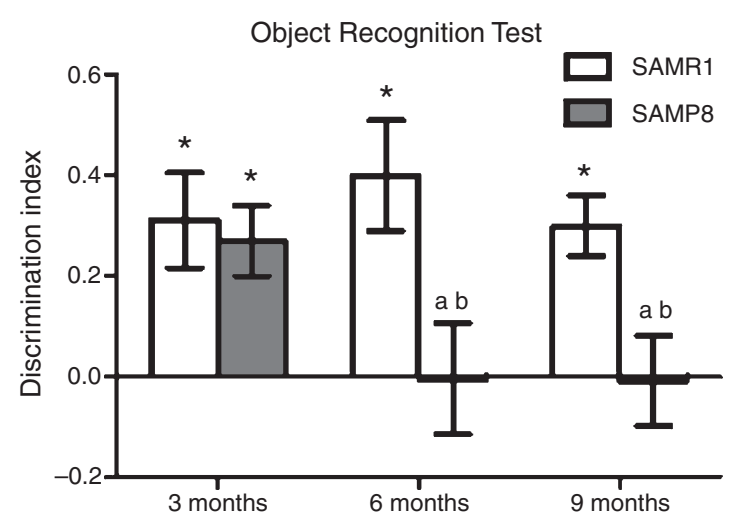

Fig. 2. Discrimination index in the object recognition test. All ages and groups except 6 and 9-month-old SAMP8 mice exhibited a positive discrimination index different from zero $* p<0.01$, onesample $t$-test versus zero). Six- and nine-month-old SAMP8 mice had a significantly lower discrimination index than aged-matched SAMR1 mice ( ${ }^{\mathrm{a}} p<0.05$ versus age-matched SAMR1, ${ }^{\mathrm{b}} p<0.001$ vs. 3-month-old SAMP8, student's $t$-test). Data is presented as mean \pm SEM.

\section{Synaptophysin levels}

Levels of synaptophysin, a marker of neurotransmission, were determined in all groups. The synaptophysin levels of 3-month-old SAMR1 mice are expressed as $100 \%$ of synaptophysin and all the other groups are referred to this standard. Figure 3 shows that there were no differences between the two strains at three months of age. However, 6- and 9-month-old SAMP8 mice had lower synaptophysin expression in the hippocampus than age-matched SAMR1 mice (Fig. 3).

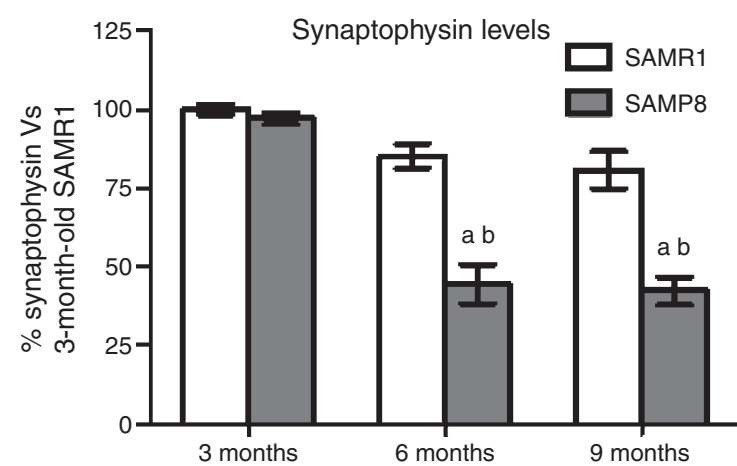

Fig. 3. Percentage of synaptophysin levels compared to 3-monthold SAMR1 mice (100\%). Six- and nine-month SAMP8 animals had lower synaptophysin expression than age-matched SAMR1 mice $\left({ }^{\mathrm{a}} p<0.001\right.$ versus age-matched SAMR1, ANOVA followed by Bonferroni's post-test). Synaptophysin levels decreased with age in SAMP8 mice ( ${ }^{\mathrm{a}} p<0.001$ versus age-matched SAMR $1,{ }^{\mathrm{b}} p<0.001$ versus 3-month-old SAMP8, ANOVA followed by Bonferroni's post-test). Data is presented as means \pm SEM.

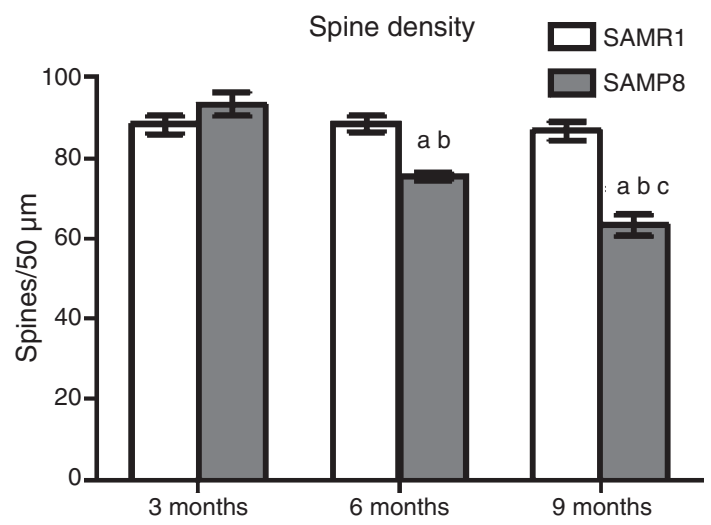

Fig. 4. Spine numerical density in CA1 pyramidal neurons of SAMP8 and SAMR1 mice. Six- and nine-month SAMP8 animals had fewer spines than age-matched SAMR1 animals $\left({ }^{\mathrm{a}} p<0.001\right.$ versus age-matched SAMR1, ANOVA followed by Bonferroni's post-test). The spine number diminished with age in SAMP8 mice ( ${ }^{\mathrm{b}} p<0.001$ versus 3 -month-old SAMP8, ${ }^{\mathrm{c}} p<0.01$ versus 6 -monthold SAMP8, ANOVA followed by Bonferroni's post-test). Data is presented as means \pm SEM. 
A time-course analysis of synaptophysin levels was also conducted, showing that SAMP8 animals present lower synaptophysin levels at 6 and 9 months of age than 3-month-old SAMP8 animals. Although SAMR1 mice seem to show less synaptophysin at 9 months than at 3 months, no statistical differences were seen. This observation indicates that there are fewer synapses in SAMP8 from 6 months onwards than in age-matched SAMR1 animals. It also shows that the loss of synapses starts as early as 6 months, compared to young individuals.

\section{Dendritic spines}

Dendritic spine density in SAMR1 mice was similar in all age groups $(\mathrm{F}=0.170, p<0.845)$ (Figs. 4 and 5). In contrast, SAMP8 mice showed significant differences in spine density $(\mathrm{F}=42.061, p<0.001)$. Both 6-month-old $(p<0.001)$ and 9-month-old $(p<0.001)$ SAMP8 mice had less dendritic spines than 3-monthold SAMP8 mice. In addition, 9-month-old SAMP8 mice had less dendritic spine density than 6-monthold SAMP8 mice $(p<0.01)$ (Figs. 4 and 5). SAMR1 and SAMP8 mice had similar numbers of dendritic spines at 3 months of age. However, at $6(p<0.001)$ and $9(p<0.001)$ months of age, SAMP8 mice had less spines than SAMR1 mice (Figs. 4 and 5).

The proportional density of thin, stubby, and mushroom spines of SAMR1 mice was the same in all age groups (data not shown). In contrast, the proportional density of thin spines varied in SAMP8 mice $(\mathrm{F}=19.291, p<0.001)$. Nine-month-old SAMP8 mice

Table 1

Spine types in SAMP8. Results are presented as mean \pm SEM

\begin{tabular}{lccc}
\hline Months-old & 3 & 6 & 9 \\
\hline Spine Proportion $(\%)$ & & & \\
Thin & $40.7 \pm 1.0$ & $43.2 \pm 0.9$ & $35.6 \pm 0.5^{\mathrm{a}, \mathrm{b}}$ \\
Stubby & $19.9 \pm 0.6$ & $18.3 \pm 0.7$ & $21.8 \pm 1.3$ \\
Mushroom & $34.9 \pm 0.8$ & $33.6 \pm 0.7$ & $36.8 \pm 1.2$ \\
\hline
\end{tabular}

${ }^{\mathrm{a}} p<0.001$ versus 3 -month-old SAMP8, ${ }^{\mathrm{b}} p<0.001$ versus 6 -monthold SAMP8, ANOVA followed by Bonferroni's post-test.

Table 2

Spine types in 6-month-old SAMR1 and SAMP8. Results are presented as a mean \pm SEM

\begin{tabular}{lcc}
\hline Strain & SAMR1 & SAMP8 \\
\hline Spine Proportion $(\%)$ & & \\
Thin & $38.7 \pm 1.1$ & $43.2 \pm 0.9^{\mathrm{a}}$ \\
Stubby & $19.0 \pm 0.61$ & $18.3 \pm 0.7$ \\
Mushroom & $38.2 \pm 1.6$ & $33.6 \pm 0.7^{\mathrm{a}}$ \\
\hline${ }^{\mathrm{a}} \mathrm{p}<0.01$ versus age-matched SAMR1, ANOVA followed by Bon- \\
ferroni's post-test.
\end{tabular}

had less thin spines than both 3 -month-old $(p<0.01)$ and 6-month-old $(p<0.001)$ SAMP8 mice. There were no differences in the proportional density of stubby or mushroom spines among all ages (Table 1). The thin, stubby, and mushroom spine proportional density was no different in the two strains at 3 and 9 months of age (data not shown), whilst there were more thin spines $(p<0.01)$ and less mushroom spines $(p<0.01)$ in 6-month-old SAMP8 mice than in the age-matched SAMR1 (Table 2).

\section{DISCUSSION}

The structural plasticity of dendritic spines, including the spine number and morphology, are crucial to learning and memory in the cerebral cortex [28]. Dendritic spine loss is observed in the hippocampus and throughout the cortex, which are the main areas affected by AD [29]. Although there is a loss of synapses in the aging brain [30], the density of dendritic spines is severely decreased in AD. This decline, rather than the amyloid burden or tau hyperphosphorylation, is the hallmark of $\mathrm{AD}$ that best correlates with cognitive decline [31]. In addition, it has been reported that several presynaptic terminal proteins are affected in multiple brain regions of patients with AD [32]. Taking all this into account, it has been proposed that the loss of dendritic spine density is indeed a critical event in the pathophysiology of AD [33].

Studies in A $\beta P P$ transgenic mice have shown functional deficits and synaptic loss before the onset of amyloid- $\beta$ plaque formation [34] and neurofibrillary tangle formation [35]. Furthermore, several studies have characterized alterations in the dendritic spine density in mouse models of $\mathrm{AD}$, such as a significant decrease in spine density of the dendrites in the hippocampus of the J20 and A $\beta P P / P S 1$ mice [26] and in the CA1 subzone both in Tg2576 and A $\beta P P / L o$ mice [36]. However, although synaptic plasticity alterations have been described in SAMP8 mice [6], no focus on the dendritic spine state has been made.

In this study, we used modified Golgi staining to compare the spine density of SAMP8 animals with that found in the genetically related control strain SAMR1 at 3,6, and 9 months of age. We found that spine density is reduced in SAMP8 mice at 6 months of age, which is also the age when the amyloid burden is increased [11] and some other protein aggregates are found [21], and pretty similar to the age when tau hyperphosphorylation is increased [12]. Likewise, spine density was also reduced in SAMP8 mice at 9 months of age. 

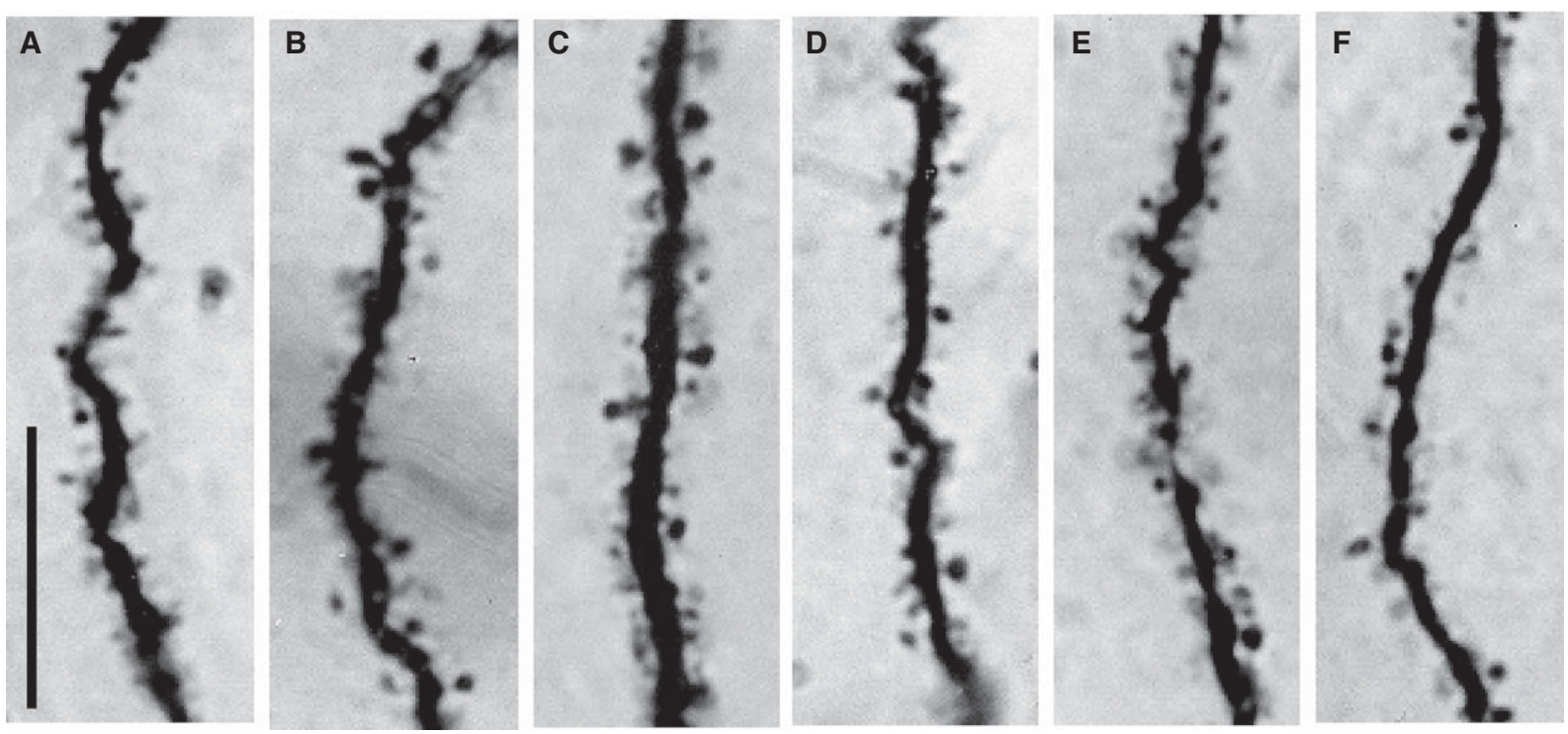

Fig. 5. Representative images of Golgi stained CA1 dendrites used to quantify and characterize dendritic spines in all groups studied. A) 3-month-old SAMR1, B) 3-month-old SAMP8, C) 6-month-old SAMR1, D) 6-month-old SAMP8, E) 9-month-old SAMR1, F) 9-month-old SAMP8. Scale bar: $10 \mu \mathrm{m}$.

SAMP8 and SAMR1 differed in terms of changes in the proportion of the various spine morphologies. In SAMR1 mice, studies and comparisons of the three ages showed similar proportional densities of thin, stubby, and mushroom spines. In contrast, the proportion of thin spines was less in SAMP8 mice at 9 months of age than at both 3 and 6 months of age. This suggests that the learning capabilities of SAMP8 mice decrease, since thin spines have been related with information acquisition (learning) [37-39]. This is in agreement with the finding that SAMP8 mice were inefficient at resolving the ORT at 9 months of age. However, 6-month-old SAMP8 mice had more thin spines than SAMR1 animals at this age, which suggests that compensatory plastic changes takes place in the development of the SAMP8 hippocampus over time. This is consistent with the fact that mushroom spines were proportionally less in SAMP8 mice than in SAMR 1 animals, at the same age. The morphophysiological properties of mushroom spines are closely related to memory storage [37-39], which suggests that although SAMP8 mice could be particularly sensitive to novel stimuli, their capacity to retain and store incoming information would be limited, at least at 6 months of age. This would be in agreement with our behavioral findings, which revealed that the discrimination index in the ORT was significantly lower in SAMP8 than in SAMR1 mice from 6 months onwards. Thus, both dendritic spine reduction and plastic changes in the types of dendritic spines in SAMP8 mice could be closely related with the behavioral inefficacy seen in SAMP8 mice in comparison with control SAMR1 mice.

Synaptic vesicle protein synaptophysin is a marker of synapses [40] and indicates the strength of synaptic transmission. We found that changes in the levels of this protein in SAMP8, which result in a significant age-related reduction in protein levels. Moreover, the content of synaptophysin in SAMR1 is similar at different ages, which confirms the analysis of dendritic spines. Intriguingly, synaptophysin levels start to decrease at 6 months of age in SAMP8 animals, which is the age when their spine density is also reduced.

In this study, we compared performance in the ORT as a measure of memory alterations in SAMP8 mice using age-matched control SAMR1 mice. The ORT is thought to critically depend on the entorhinal cortex, hippocampus, and frontal cortex and is considered a test of short-term memory [41]. In AD, alterations in these brain structures as well as impairment in short-term memory have been widely reported in the literature. Our results show that from 6 months onwards SAMP8 mice show an impaired memory. At this age, when their levels of synaptophysin and spine density are decreased. Interestingly, 9-month-old SAMP8 mice show the same poor performance in ORT with the same decreased synaptophysin levels, but with less spine density than 6-month-old SAMP8. In contrast, SAMR1 animals show no alterations in shortterm memory, synaptophysin levels, or spine density 
from 3 to 9 months of age. These facts can be related with the persistence of spines in SAMR1 which have a stable density throughout the animals' lives. This stability allows the memory circuits to be consolidated for a long time.

Several studies in the literature established that amyloid- $\beta$ oligomers and plaques in AD patients or experimental models first induce tau phosphorylation, and then produce cytoskeletal collapse and neuritic degeneration [42]. We demonstrated that in a bonafide murine model of senescence and AD pathology, such as SAMP8 strain, synaptic, dendritic, and memory alterations appear from 6 months onwards. This reinforces the growing interest in SAMP8 as a model of $\mathrm{AD}$.

\section{ACKNOWLEDGMENTS}

We thank the Language Advisory Service of the University of Barcelona for revising the manuscript. This study was supported by grants SAF-2009-13093 and SAF-2011-23631 from the "Ministerio de Educación y Ciencia" and DPS2008-06998-C01,C02 from the "Instituto de Salud Carlos III", 2009/SGR00893 from the "Generalitat de Catalunya" and 610RT0405 from the Programa Iberoamericano de Ciencia y Tecnologia para el Desarrollo (CYTED).

Authors' disclosures available online (http://www.jalz.com/disclosures/view.php?id=1380).

\section{REFERENCES}

[1] Takeda T, Hosokawa M, Takeshita S, Irino M, Higuchi K, Matsushita T, Tomita Y, Yasuhira K, Hamamoto H, Shimizu K, Ishii M, Yamamuro T (1981) A new murine model of accelerated senescence. Mech Ageing Dev 17, 183194.

[2] Hamamoto H, Honma A, Irino I, Matsushita T, Toda K, Matsumura M, Takeda T (1984) Grading score system: A method for evaluation of the degree of senescence in senescence accelerated mouse (SAM). Mech Ageing Dev 26, 91-102.

[3] Takeda T, Hosokawa M, Higuchi K, Hosono M, Akiguchi I, Katoh H (1994) A novel murine model of aging, SenescenceAccelerated Mouse (SAM). Arch Gerontol Geriatr 19, 185192.

[4] Yagi H, Irino M, Matsushita T, Katoh S, Umezawa M, Tsuboyama T, Hosokawa M, Akiguchi I, Tokunaga R, Takeda T (1989) Spontaneous spongy degeneration of the brain stem in SAM-P/8 mice, a newly developed memory-deficient strain. J Neuropathol Exp Neurol 48, 577-590.

[5] Kawamata T, Nakamura S, Akiguchi I (1994) Dystrophic changes in axon accumulating nitric oxide synthase are accelerated with age in dorsal colime nuclei of senescenceaccelerated mice (SAMP8). In The SAM model of senescence. Takeda T (Ed). Elsevier Sciences BV, Amsterdam, pp $347-$ 350 .
[6] Nomura Y, Okuma Y (1999) Age-related defects in lifespan and learning ability in. SAMP8 mice. Neurobiol Aging 20, 111-115.

[7] Takeda T (2009) Senescence-accelerated mouse (SAM) with special references to neurodegeneration models, SAMP8 and SAMP10 mice. Neurochem Res 34, 639-659.

[8] Morley JE (2002) The SAMP8 mouse: A model of Alzheimer disease? Biogerontology 3, 57-60.

[9] Miyamoto M, Kiyota Y, Yamazaki N, Nagaoka A, Matsuo T, Nagawa Y, Takeda T (1986) Age-related changes in learning and memory in the senescence-accelerated mouse (SAM). Physiol Behav 38, 399-406.

[10] Spangler EL, Patel N, Speer D, Hyman M, Hengemihle J, Markowska A, Ingram DK (2002) Passive avoidance and complex maze learning in the senescence accelerated mouse (SAM): Age and strain comparisons of SAM P8 and R1. J Gerontol A Biol Sci Med Sci 57, B61-B68.

[11] Del Valle J, Duran-Vilaregut J, Manich G, Casadesús G, Smith MA, Camins A, Pallàs M, Pelegrí C, Vilaplana J (2010) Early amyloid accumulation in the hippocampus of SAMP8 mice. J Alzheimers Dis 19, 1303-1315.

[12] Canudas AM, Gutierrez-Cuesta J, Rodríguez MI, AcuñaCastroviejo D, Sureda FX, Camins A, Pallàs M (2005) Hyperphosphorylation of microtubule-associated protein tau in senescence-accelerated mouse (SAM). Mech Ageing Dev 126, 1300-1304.

[13] Del Valle J, Duran-Vilaregut J, Manich G, Pallàs M, Camins A, Vilaplana J, Pelegrí C (2011) Cerebral amyloid angiopathy, blood-brain barrier disruption and amyloid accumulation in SAMP8 mice. Neurodegener Dis 8, 421-429.

[14] Pelegrí C, Canudas AM, del Valle J, Casadesus G, Smith MA, Camins A, Pallàs M, Vilaplana J (2007) Increased permeability of blood-brain barrier on the hippocampus of a murine model of senescence. Mech Ageing Dev 128, 522528.

[15] Del Valle J, Duran-Vilaregut J, Manich G, Camins A, Pallàs M, Vilaplana J, Pelegrí C (2009) Time-course of blood-brain barrier disruption in senescence-accelerated mouse prone 8 (SAMP8) mice. Int J Dev Neurosci 27, 47-52.

[16] Alvarez-García O, Vega-Naredo I, Sierra V, Caballero B, Tomás-Zapico C, Camins A, García JJ, Pallàs M, CotoMontes A (2006) Elevated oxidative stress in the brain of senescence-accelerated mice at 5 months of age. Biogerontology 7, 43-52.

[17] Onozuka M, Watanabe K, Fujita M, Tomida M, Ozono S (2002) Changes in the septohippocampal cholinergic system following removal of molar teeth in the aged SAMP8 mouse. Behav Brain Res 133, 197-204.

[18] Zhao XH, Nomura Y (1990) Age-related changes in uptake and release on $\mathrm{L}-[3 \mathrm{H}]$ noradrenaline in brain slices of senescence accelerated mouse. Int J Dev Neurosci 8, 267-272.

[19] Zhao XH, Kitamura Y, Nomura Y (1992) Age-related changes in NMDA-induced [3H]acetylcholine release from brain slices of senescence-accelerated mouse. Int J Dev Neurosci 10, 121-129.

[20] Miyamoto M (1997) Characteristics of age-related behavioral changes in senescence-accelerated mouse SAMP8 and SAMP10. Exp Gerontol 32, 139-148.

[21] Manich G, Mercader C, del Valle J, Duran-Vilaregut J, Camins A, Pallàs M, Vilaplana J, Pelegrí C (2011) Characterization of amyloid- $\beta$ granules in the hippocampus of SAMP8 mice. J Alzheimers Dis 25, 535-546.

[22] González-Burgos I (2012) From synaptic transmission to cognition: An intermediary role for dendritic spines. Brain Cogn. doi: 10.1016/j.bandc.2012.03.002. 
[23] González-Burgos I (2009) Dendritic spines plasticity and learning/memory processes: Theory, evidence and perspectives. In Dendritic spines. Biochemistry, modelling and properties, Neuroscience research progress series, Baylog LR (Ed). Nova Science Publishers, Inc. New York, pp. 163186.

[24] Knobloch M, Mansuy IM (2008) Dendritic spine loss and synaptic alterations in Alzheimer's disease. Mol Neurobiol 37, 73-82.

[25] Smith DL, Pozueta J, Gong B, Arancio O, Shelanski M (2009) Reversal of long-term dendritic spine alterations in Alzheimer disease models. Proc Natl Acad Sci U S A 106, 16877-16882.

[26] Moolman DL, Vitolo OV, Vonsattel JP, Shelanski ML (2004) Dendrite and dendritic spine alterations in Alzheimer models. J Neurocytol 33, 377-387.

[27] Gonzalez-Burgos I, Tapia-Arizmendi G, Feria-Velasco A (1992) Golgi method without osmium tetroxide for the study of the central nervous system. Biotech Histochem 67, 288296.

[28] Lamprecht R, LeDoux J (2004) Structural plasticity and memory. Nat Rev Neurosci 5, 45-54.

[29] Penzes P, Cahill ME, Jones KE, VanLeeuwen JE, Woolfrey KE (2011) Dendritic spine pathology in neuropsychiatric disorders. Nature Neurosci 14, 285-293.

[30] Hof PR, Morrison JH (2004) The aging brain: Morphomolecular senescence of cortical circuits. Trends Neurosci 27, 607-613.

[31] Masliah E, Crews L, Hansen L (2006) Synaptic remodeling during aging and in Alzheimer's disease. J Alzheimers Dis $\mathbf{9}$, 91-99.

[32] Honer WG (2003) Pathology of presynaptic proteins in Alzheimer's disease: More than simple loss of terminals. Neurobiol Aging 24, 1047-1062.

[33] Palop JJ, Mucke L (2010) Amyloid-beta-induced neuronal dysfunction in Alzheimer's disease: From synapses toward neural networks. Nat Neurosci 13, 812-818.
[34] Hsia AY, Masliah E, McConlogue L, Yu GQ, Tatsuno G, Hu K, Kholodenko D, Malenka RC, Nicoll RA, Mucke L (1999) Plaque-independent disruption of neural circuits in Alzheimer's disease mouse models. Proc Natl Acad Sci U S A 96, 3228-3233.

[35] Yoshiyama Y, Higuchi M, Zhang B, Huang SM, Iwata N, Saido TC, Maeda J, Suhara T, Trojanowski JQ, Lee VM (2007) Synapse loss and microglial activation precede tangles in a P301S tauopathy mouse model. Neuron 53, 337-351.

[36] Perez-Cruz C, Nolte MW, van Gaalen MM, Rustay NR, Termont A, Tanghe A, Kirchhoff F, Ebert U (2011) Reduced spine density in specific regions of CA1 pyramidal neurons in two transgenic mouse models of Alzheimer's disease. J Neurosci 31, 3926-3934.

[37] Kasai H, Fukuda M, Watanabe S, Hayashi-Takagi A, Noguchi J (2010) Structural dynamics of dendritic spines in memory and cognition. Trends Neurosci 33, 121-129.

[38] Bourne J, Harris KM (2007) Do thin spines learn to be mushroom spines that remember? Curr Opin Neurobiol 17, 381-386.

[39] Kasai H, Matsuzaki M, Noguchi J, Yasumatsu N, Nakahara H (2003) Structure-stability-function relationships of dendritic spines. Trends Neurosci 26, 360-368.

[40] Kashani A, Lepicard E, Poirel O, Videau C, David JP, FalletBianco C, Simon A, Delacourte A, Giros B, Epelbaum J, Betancur C, El Mestikawy S (2008) Loss of VGLUT1 and VGLUT2 in the prefrontal cortex is correlated with cognitive decline in Alzheimer disease. Neurobiol Aging 29, 16191630 .

[41] Mitchell JB, Laiacona J (1998) The medial frontal cortex and temporal memory: Tests using spontaneous exploratory behavior in the rat. Behav Brain Res 97, 107-113.

[42] Jin M, Shepardson N, Yang T, Chen G, Walsh D, Selkoe DJ (2011) Soluble amyloid beta-protein dimers isolated from Alzheimer cortex directly induce Tau hyperphosphorylation and neuritic degeneration. Proc Natl Acad Sci U S A $\mathbf{1 0 8}$, 5819-5824. 